\title{
Dysregulated Dermal Mesenchymal Stem Cell Proliferation and Differentiation Interfered by Glucose Metabolism in Psoriasis
}

\author{
Xincheng Zhao, Jianxiao Xing, Junqin Li, Ruixia Hou, Xuping Niu, Ruifeng Liu, \\ Juanjuan Jiao, Xiaohong Yang, Juan Li, Jiannan Liang, Ling Zhou, Qiang Wang, \\ Wenjuan Chang, Guohua Yin, Xinhua Li, Kaiming Zhang
}

Shanxi Key Laboratory of Stem Cell for Immunological Dermatosis, Institute of Dermatology, Taiyuan City Centre Hospital of Shanxi Medical University, Taiyuan, China

Background and Objectives: Psoriasis is a chronic inflammatory skin disease, which the mechanisms behind its initiation and development are related to many factors. DMSCs (dermal mesenchymal stem cells) represent an important member of the skin microenvironment and play an important role in the surrounding environment and in neighbouring cells, but they are also affected by the microenvironment. We studied the glucose metabolism of DMSCs in psoriasis patients and a control group to reveal the relationship among glucose metabolism, cell proliferation activity, and VEC (vascular endothelial cell) differentiation in vitro, we demonstrated the biological activity and molecular mechanisms of DMSCs in psoriasis.

Methods and Results: We found that the OCR of DMSCs in psoriatic lesions was higher than that in the control group, and mRNA of GLUT1 and HK2 were up-regulated compared with the control group. The proliferative activity of DMSCs in psoriasis was reduced at an early stage, and mRNA involved in proliferation, JUNB and FOS were expressed at lower levels than those in the control group. The number of blood vessels in psoriatic lesions was significantly higher than that in the control group $(\mathrm{p}<0.05)$, which the mRNA of VEC differentiation, CXCL12, CXCR7, HEYL and RGS5 tended to be increased in psoriatic lesions compared to the control group, in addition to Notch3. Conclusions: We speculated that DMSCs affected local psoriatic blood vessels through glucose metabolism, and the differentiation of VECs, which resulted in the pathophysiological process of psoriasis.

Keywords: Cell proliferation, DMSCs, Glucose metabolism, Psoriasis, Vascular differention

Received: May 1, 2020, Revised: September 30, 2020, Accepted: October 12, 2020, Published online: February 28, 2021 Correspondence to Kaiming Zhang

Shanxi Key Laboratory of Stem Cell for Immunological Dermatosis, Institute of Dermatology, Taiyuan City Centre Hospital of Shanxi Medical University, No.5, east third lane, Jiefang road, Taiyuan, Shanxi 030009, China

Tel: +86-(0)-351-5656076, Fax: +86-(0)-351-5656080

E-mail: zhangkaiming@sina.com

(c) This is an open-access article distributed under the terms of the Creative Commons Attribution Non-Commercial License (http://creativecommons.org/ licenses/by-nc/4.0/), which permits unrestricted non-commercial use, distribution, and reproduction in any medium, provided the original work is properly cited.

Copyright (c) 2021 by the Korean Society for Stem Cell Research

\section{Introduction}

Psoriasis is a chronic inflammatory skin disease with a long course and a tendency towards palindromia, and it has a great impact on the patient's quality of life, its rates are much higher than those of cancer, myocardial infarction and congestive heart failure, and they are only second to mental diseases (1-3). While keratinocyte proliferation, lymphocyte infiltration, dermal vascular hyperplasia and dilation are the main histopathological features of psoriasis, it is also considered a systemic disease with multiple cardiovascular and metabolic comorbidities (4). 
Zhang et al. (5) found glucose uptake is critical for rapid keratinocyte proliferation and is an efficient response to psoriasis of physiologically relevant stressors including full-thickness wounds and UV-B irradiation.

MSCs (mesenchymal stem cells) participate in the occurrence and development of multifarious diseases and play a role in immune regulation and angiogenesis (6), therefore, they have great potential in the treatment of diseases (7). Clinical studies have shown that MSC infusion can significantly reduce the severity of psoriasis $(8,9)$. DMSCs are important members of the skin microenvironment, and they have gradually become the focus of dermatological researchers in recent years.

The biological activity profile of DMSCs influenced by psoriatic microenvironment remain unknown. We previously conducted a large number of studies on DMSCs in psoriasis, and the results showed that DMSCs from psoriatic patients secreted abnormal cytokines and that their DNA methylation was abnormal $(10,11)$. Li et al. (12) demonstrate that psoriatic DMSCs increase keratinocyte proliferation and glycolysis, and reduce cell junctions, suggesting a pathogenic role of psoriatic DMSCs in epidermal hyperplasia, aberrant differentiation, and reduction in turnover time of keratinocytes in psoriasis. How glucose metabolish influenced the DMSCs in psoriasis has not been explored. To further clarify the biologically abnormal mechanism of DMSCs in psoriasis, we detected the glucose metabolism level, cell proliferation, angiogenesis and VEC differentiation in psoriatic DMSCs.

\section{Materials and Methods}

\section{Subjects}

We chose 16 psoriasis patients ( 8 men and 8 women, ages 19 55, PASI score $17.67 \pm 6.19)$ who visited our Hospital and had no systemic diseases or treatments with corticosteroids, immunosuppressive agents, or ultraviolet phototherapy within the 3 months before enrolment. The control samples ( 8 men and 8 women, age $25 \sim 55$ ) were enrolled from the Urology and Plastic Surgery Department of our Hospital.

All participants signed informed consent, and the protocol was approved by the Medical Ethics Committee of our Hospital and was in accord with the Declaration of Helsinki.

\section{Isolation and identification of DMSCs}

The specimens without adipose layers that were cut into pieces by scissors, the epidermis and dermis were separated by treatment with $0.25 \%$ dispase enzyme (Sigma
Aldrich, St. Louis, MO, USA). The dermis was minced finely and turned into a single cell suspension. Cells were then cultured in DMEM/F12 (HyClone, USA)containing 10\% FBS (HyClone, USA), $10 \mu \mathrm{l} / \mathrm{ml} \mathrm{B27}$ (Invitrogen, US), $100 \mathrm{U} / \mathrm{ml}$ penicillin (Sigma-Aldrich, St. Louis, MO, USA) and $100 \mu \mathrm{g} / \mathrm{ml}$ streptomycin (Sigma-Aldrich, St. Louis, MO, USA) at $37^{\circ} \mathrm{C}$ with $5 \% \mathrm{CO}_{2}$. The non-adherent cells were removed after $48 \mathrm{~h}$, and the remaining cells were cultured with passaging. DMSCs were identified using flow cytometry to analyse CD29 (Backman, USA), CD44 (Backman, USA), CD105 (Backman, USA), CD34 (Backman, USA), CD45 (Backman, USA), HLA-DR (Backman, USA), Dil-LDL (Sigma-Aldrich, St. Louis, MO, USA), and UEA-1-FITC (Sigma-Aldrich, St. Louis, MO, USA). Identification was also performed on differentiated adipocytes, osteoclasts and VECs. The specific methods followed published protocols $(13,14)$.

\section{Cellular bioenergetic function analysis}

The DMSC OCRs were measured with an XF Cell Mito Stress Test Kit (Seahorse Bioscience) $(15,16)$. The kit includes the following inhibitors which were oligomycin, FCCP and rotenone/antimycin-A. Oligomycin was added to evaluate ATP-linked and proton leak respiration. FCCP was added to evaluate maximal respiration and reserve capacity. Antimycin A was added to evaluate non-mitochondrial OCR (Fig. 1A).

\section{Analysis of DMSC proliferation}

The isolated DMSCs were diluted with DMEM/F12 medium and then inoculated into the 24-hole culture plate at a density of $2 \times 10^{5} / \mathrm{ml}$ to be maintained at $37^{\circ} \mathrm{C}$ and $5 \% \mathrm{CO}_{2}$. Half of the medium was replaced every third day. DMSCs were stained with trypan blue and counted every 3 days using an Invitrogen cell counter (Countess II Automated Cell Counter, Thermo Fisher Scientific).

\section{Blood vessel counts and pathology}

Standard HE staining procedures were followed. First, samples were preserved in $4 \%$ formaldehyde, followed by dehydration, embedding, impregnation, staining and sealing. An inverted phase contrast microscope (OlympusIMT2) was used for microscopic observation. Five visual fields were randomly selected from each section, blood vessels were identified, and the mean number of blood vessels was calculated.

\section{RNA extraction and qRT-PCR}

Total RNA from DMSCs was extracted using Trizol (Invitrogen, USA), RNA purity was determined (Biodrop, 
A
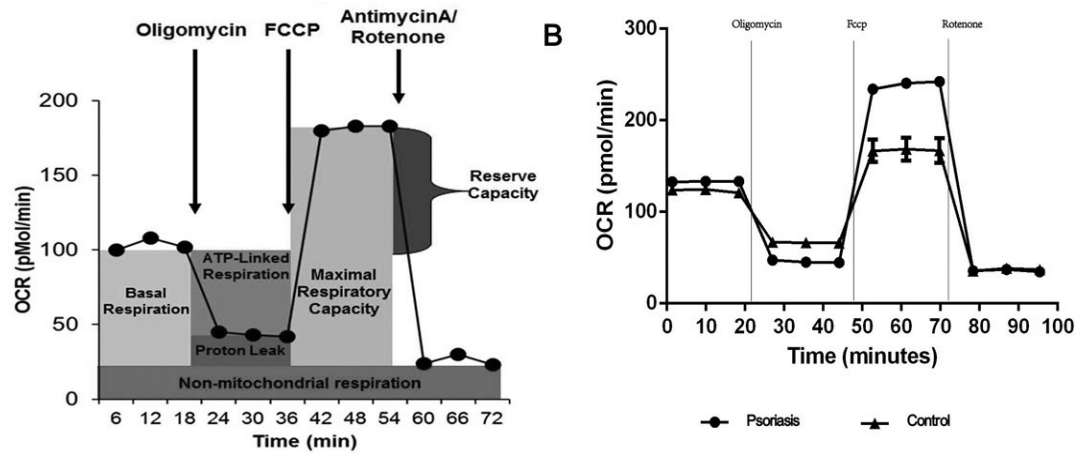

C

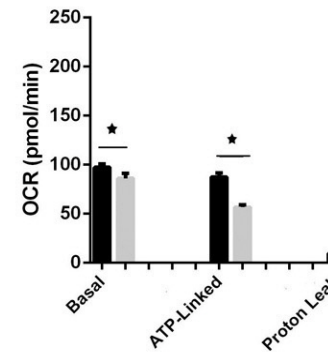

D

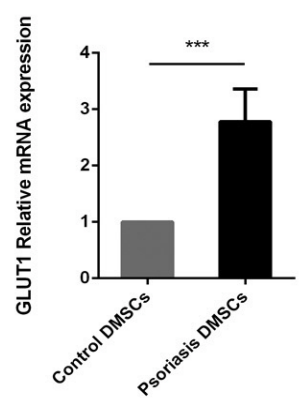

E
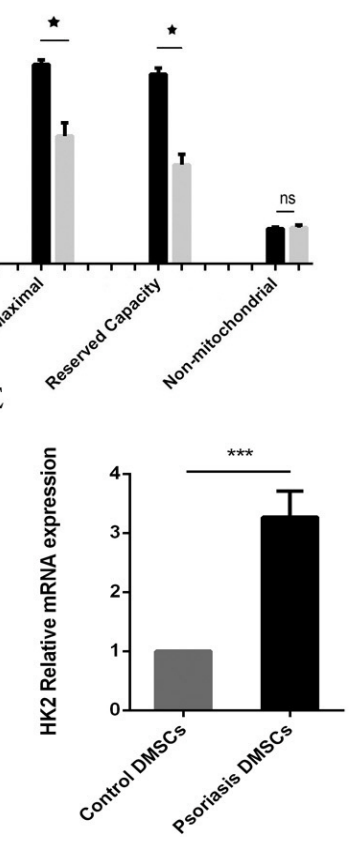

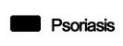

Contol
Control DMSCs Psoriasis DMSCs
Fig. 1. The metabolic profile of DMSCs. Basal OCR was measured before oligomycin treatment, and it was subtracted after rotenone/antimycin treatment. (A) ATP-linked OCR was calculated by subtracting the basal OCR from the amount of respiration left after oligomycin was added. Proton leakage was determined by subtracting the non-mitochondrial OCR from the amount of respiration left after oligomycin was added. Maximal respiration was calculated by subtracting the maximal OCR from the non-mitochondrial OCR. The reserve capacity was determined by subtracting the maximal OCR from the basal OCR. (B) $\mathrm{O} 2$ consumption in the DMSCs of the psoriasis and control groups. The rates of O2 (OCR) were first measured in DMSCs under basal conditions and then sequentially after the addition of oligomycin $(1 \mu \mathrm{M})$, carbonylcyanidep-(trifluoromethoxy), phenylhydrazone (FCCP) $(2 \mu \mathrm{M})$, and rotenone $(0.5 \mu \mathrm{M})$. (C) Graphs show the ATP-linked OCR, proton leak OCR, maximal OCR, reserve capacity and non-mitochondrial OCR in the psoriasis and control groups. (D, E) Histograms showing the relative mRNA expression levels of GLUT1 and HK2. ns $\mathrm{p}>0.05,{ }^{*} \mathrm{p}<$ $0.05, * * * \mathrm{p}<0.001$.
CO, UK), and cDNA was synthesized (Takara, Shiga, Japan). cDNA was synthesized using 5X PrimeScript RT Master Mix $(2 \mu \mathrm{l})$ and total RNA and RNase Free dH2O in a total volume of $10 \mu 1$ (TaKaRa, Shiga, Japan). PCR amplification was performed in a $20 \mu 1$ reaction system containing $2 \mu 1$ template, $10 \mu 1$ TB Green Premix Ex Taq II (TaKaRa), $0.4 \mu 1$ Rox Reference Dye, $6 \mu 1$ sterile purified water, and $0.8 \mu 1$ of PCR primers. The primer sequences are shown in Table 1. Initial denaturation was performed at $95^{\circ} \mathrm{C}$ for $30 \mathrm{~s}$ and was followed by 40 cycles of denaturation at $95^{\circ} \mathrm{C}$ for $10 \mathrm{~s}$, annealing at $60^{\circ} \mathrm{C}$ for $30 \mathrm{~s}$, dissociation at $95^{\circ} \mathrm{C}$ for $15 \mathrm{~s}, 60^{\circ} \mathrm{C}$ for $1 \mathrm{~min}$, and $95^{\circ} \mathrm{C}$ for 15 s. PCR products were identified using $2 \%$ agarose gel electrophoresis.

\section{Statistical analysis}

SPSS 18.0 software was used to perform statistical analysis. The number of blood vessels and the number of cells (from proliferation) were analysed by Student's t-test, the dates expressed as mean $\pm \mathrm{SD}$ and $\mathrm{p}<0.05$ was considered to indicate statistical significance. The mRNA expression was analysed using the $2^{-\Delta 4 \mathrm{Ct}}$ method.

\section{Results}

\section{Identification of DMSCs}

The cell morphology of DMSCs was fibroblast-like in appearance with no distinct morphological differences among groups (Fig. 2A $\sim$ C). All cells showed high expression levels of CD29 (94.6\%), CD44 (92.8\%) and CD105 (95.0\%) but low expression of CD34 (0.6\%), CD45 $(0.2 \%)$ and HLA-DR (1.2\%), confirming the MSC phenotype (Fig. 2G). By culturing in specified induction medium, the cells exhibited the ability to differentiate into 
Table 1. The information of primers

\begin{tabular}{|c|c|c|c|c|}
\hline Targets & Primer sequence $\left(5^{\prime}-3^{\prime}\right)$ & $\begin{array}{c}\text { Annealing } \\
\text { temperature }\left({ }^{\circ} \mathrm{C}\right)\end{array}$ & Function & Referenced website of function \\
\hline \multirow[t]{2}{*}{ JUNB } & Sense: ACGACTCATACACAGCTACGG & \multirow[t]{2}{*}{58} & \multirow{2}{*}{$\begin{array}{l}\text { Basic cellular } \\
\text { activities }\end{array}$} & \multirow[t]{2}{*}{ https://www.ncbi.nlm.nih.gov/gene/3726 } \\
\hline & Antisense: GCTCGGTTTCAGGAGTTTGTAGT & & & \\
\hline \multirow[t]{2}{*}{ FOS } & Sense: GGGGCAAGGTGGAACAGTTAT & \multirow[t]{2}{*}{58} & \multirow{2}{*}{$\begin{array}{l}\text { Cell } \\
\text { proliferation }\end{array}$} & \multirow[t]{2}{*}{ https://www.ncbi.nlm.nih.gov/gene/2353 } \\
\hline & Antisense: CCGCTTGGAGTGTATCAGTCA & & & \\
\hline \multirow[t]{2}{*}{ CXCR7 } & Sense: TCTGCATCTCTTCGACTACTCA & \multirow[t]{2}{*}{60} & \multirow[t]{2}{*}{ Angiogenic } & \multirow[t]{2}{*}{ https://www.ncbi.nlm.nih.gov/gene/3726 } \\
\hline & Antisense: GTAGAGCAGGACGCTTTTGTT & & & \\
\hline \multirow[t]{2}{*}{ CXCL12 } & Sense: ATTCTCAACACTCCAAАCTGTGC & \multirow[t]{2}{*}{56} & \multirow[t]{2}{*}{ Angiogenic } & \multirow[t]{2}{*}{ https://www.ncbi.nlm.nih.gov/gene/6387 } \\
\hline & Antisense: ACTTTAGCTTCGGGTCAATGC & & & \\
\hline \multirow[t]{2}{*}{ RGS5 } & Sense: GACATGGCCCAGAAAAGAATCC & \multirow[t]{2}{*}{58} & \multirow[t]{2}{*}{ Angiogenic } & \multirow[t]{2}{*}{ https://www.ncbi.nlm.nih.gov/gene/8490 } \\
\hline & Antisense: CACAAAGCGAGGCAGAGAATC & & & \\
\hline \multirow[t]{2}{*}{ HEYL } & Sense: GGCTGCTTACGTGGCTGTT & \multirow[t]{2}{*}{58} & \multirow[t]{2}{*}{ Differentiation } & \multirow[t]{2}{*}{ https://www.ncbi.nlm.nih.gov/gene/26508 } \\
\hline & Antisense: GACCCAGGAGTGGTAGAGCAT & & & \\
\hline \multirow[t]{2}{*}{ Notch3 } & Sense: TGGCGACCTCACTTACGACT & \multirow[t]{2}{*}{58} & \multirow[t]{2}{*}{ Differentiation } & \multirow[t]{2}{*}{ https://www.ncbi.nlm.nih.gov/gene/4854 } \\
\hline & Antisense: CACTGGCAGTTATAGGTGTTGAC & & & \\
\hline \multirow[t]{2}{*}{ Glut1 } & Sense: CTGGCATCAACGCTGTCTTC & \multirow[t]{2}{*}{60} & \multirow{2}{*}{$\begin{array}{l}\text { Glucose } \\
\text { transporter }\end{array}$} & \multirow[t]{2}{*}{ https://www.ncbi.nlm.nih.gov/gene/38109 } \\
\hline & Antisense: GCCTATGAGGTGCAGGGTC & & & \\
\hline \multirow[t]{2}{*}{$\mathrm{Hk} 2$} & Sense: GAGCCACCACTCACCCTACT & \multirow[t]{2}{*}{60} & \multirow[t]{2}{*}{ Glycolysis } & \multirow[t]{2}{*}{ https://www.ncbi.nlm.nih.gov/gene/3099 } \\
\hline & Antisense: CCAGGCATTCGGCAATGTG & & & \\
\hline
\end{tabular}

adipocytes (Fig 2D), osteoclasts (Fig 2E) and VECs (Fig $2 \mathrm{~F}$ ), confirming the multidirectional differentiation ability of MSCs. Psoriatic DMSCs have stronger differentiation function compared to normal DMSCs, the result has been reported in our previous study (17).

\section{The glucose metabolic profile of DMSCs}

The overall OCR profile was higher in the psoriatic DMSCs compared to those from healthy subjects (Fig. 1B). The basal respiration $(\mathrm{p}<0.05)$, ATP-linked respiration $(p<0.05)$ and maximal respiration $(p<0.05)$ were significantly higher in the psoriatic DMSCs compared to the control DMSCs, but they had decreased proton leak respiration. Moreover, the reserve capacity respiration $(\mathrm{p}<$ 0.05 ) was also significantly higher in the psoriatic DMSCs, but non-mitochondrial respiration had no statistical significance (Fig. 1C). The results indicated the increased glucose levels and mitochondrial metabolism supported cellular activity.

Glucose metabolism, especially when ATP-linked, is essential for cellular activity. Glucose metabolism is linked to cell proliferation and differentiation. The link is present in many cells ranging from microorganism to $\mathrm{T}$ cells, but there is no report of such a link in DMSCs, particularly in psoriatic DMSCs.

\section{Expression of mRNA related to glucose metabolic in DMSCs}

Glut's (glucose transporters) regulate the availability of glucose for most tissues. Recent studies reveal that GLUT1 which is a member of facilitative sugar transporters, up regulation is considered to promote epidermal hyperproliferation, inflammation and angiogenesis in the pathogenesis of psoriasis (18). Hexokinases (HKs), which play a key role in the first step of glucose metabolism (19). In order to clarify the mRNA differences of glucose metabolism between psoriasis patients and normal control derived DMSCs, we detected the expression levels of GLUT1 and HK2. GLUT1 (2.78 \pm 058 -fold) and HK2 $(3.27 \pm 0.44$-fold) were up-regulated in the psoriatic DMSCs (Fig 1D and 1E).

\section{Proliferation of DMSCs}

The growth rates of DMSCs were estimated by cell count for each group, and the values are shown in Fig. $3 \mathrm{~A}$. On day 3, the cell number in DMSCs from the psoriasis group was lower $(3.76 \pm 0.32)$ than that in DMSCs from the control group $(4.0 \pm 0.18), \mathrm{p}<0.05$ (Fig 3B). However, after long-term cultures (15 days), the cell proliferation rate of psoriatic DMSCs was similar to that of the control cells $(\mathrm{p}>0.05)$.

\section{Expression of mRNA related to cell proliferation in DMSCs}

To investigate the different molecular mechanisms of cell proliferation after 3 days, we evaluated the mRNA expression of genes related to cell proliferation, including JUNB and FOS (Fig 3C and 3D). The mRNA expression 

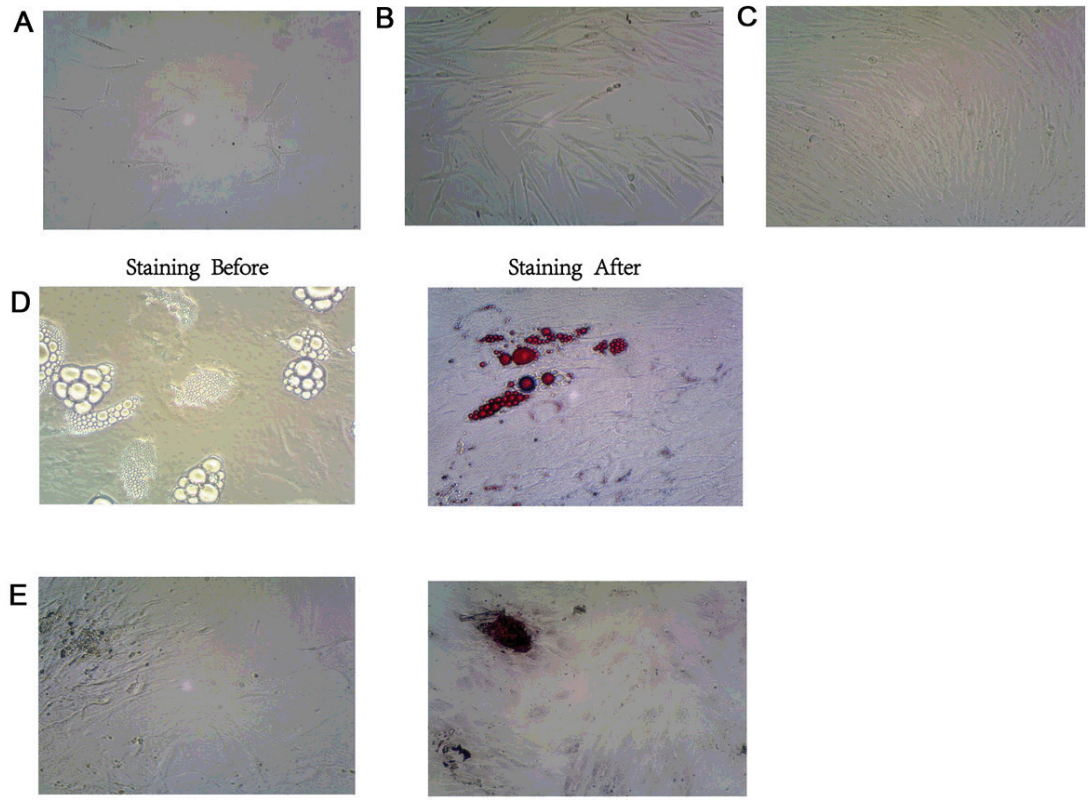

F
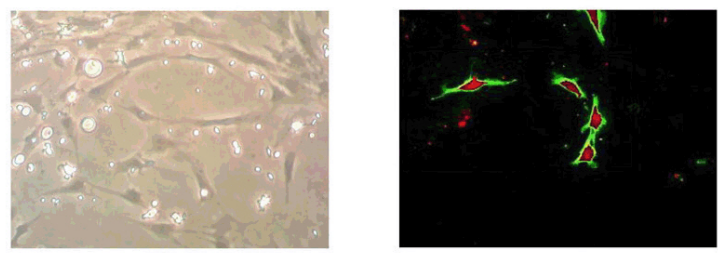

G
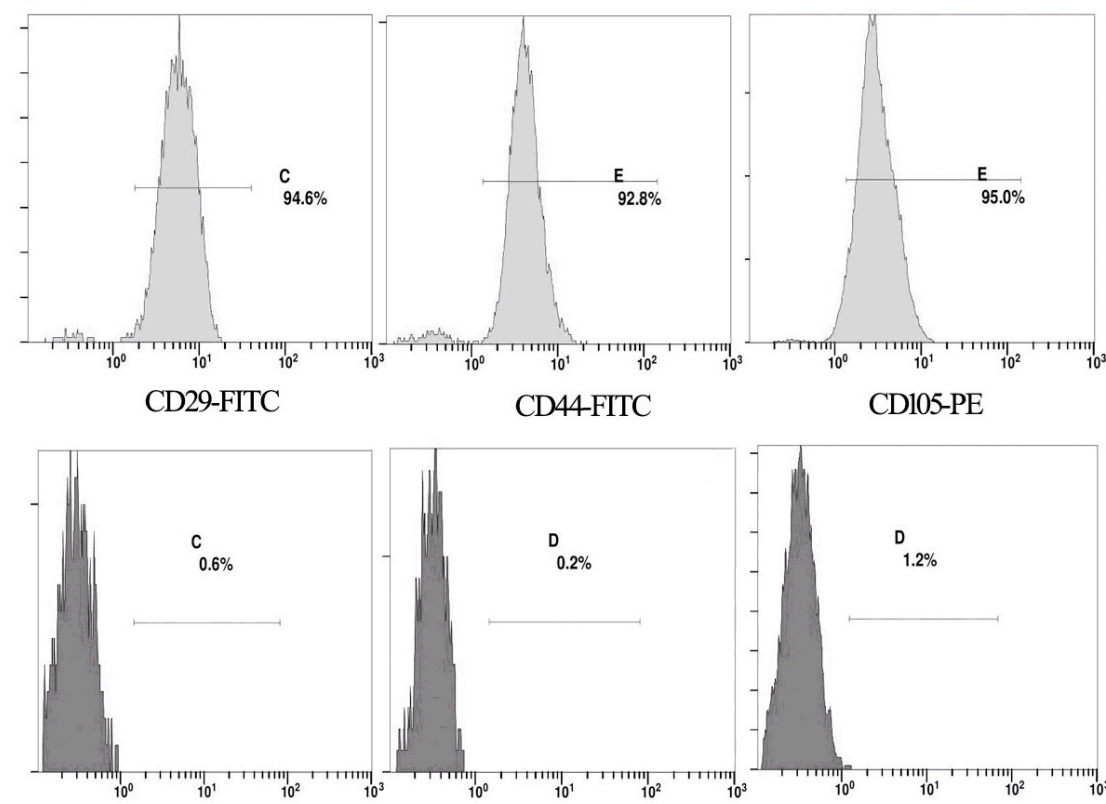

CD45-FITC

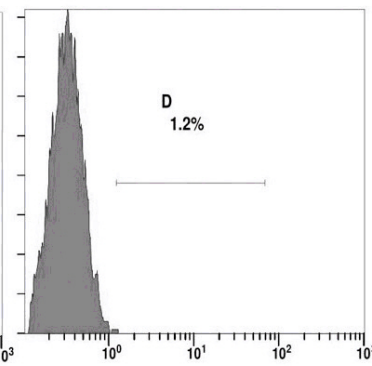

HLA-DR-FITC
Fig. 2. Identification of DMSCs. (A C) Morphological characteristics of DMSCs cultured for 6,12 and 15 days $(\times 200)$. (D, E) Morphology of adipocytes and osteoblasts generated by the induction of DMSCs; adipocytes stained before; adipocytes stained with oil red O; osteoblasts stained before; osteoblasts stained with alizarin red $(\times 400)$. (F) Angiogenic network in DMSCs after differentiation $(\times 400)$. Overlay of ac-LDL and UEA-1 in DMSCs after differentiation, the uptake of ac-LDL stimulated red fluorescence, the UEA-1stimulated green fluorescence, and the ac-LDL and UEA-1stimulated red and green fluorescence $(\times 200)$. (G) Identification of DMSCs by flow cytometry. of JUNB in psoriatic DMSCs was $(0.52 \pm 0.08)$ times what was observed in normal DMSCs. Similarly, the mRNA expression of FOS was downregulated in psoriatic DMSCs to $(0.65 \pm 0.15)$ times the levels seen in the control. 


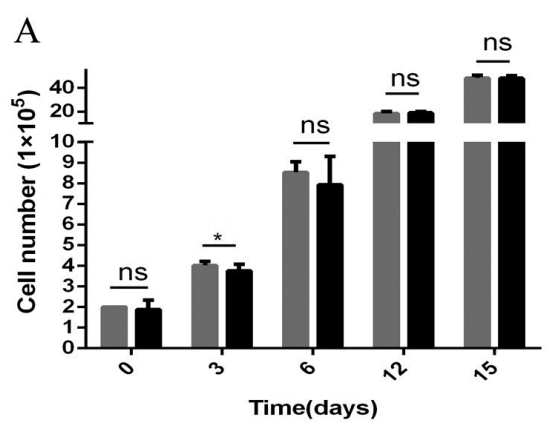

Control DMSCs

- Psoriasis DMSCs
C

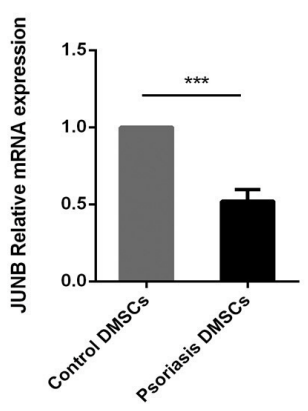

B $\triangle$ Control DMSCs

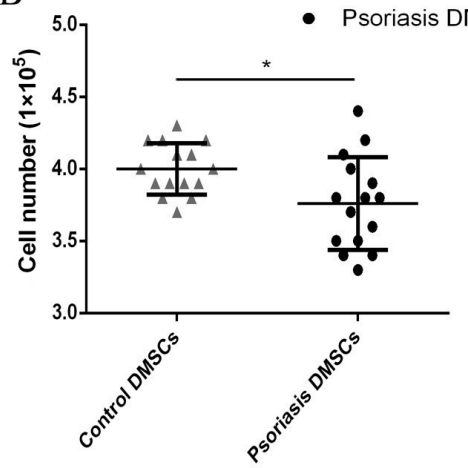

D

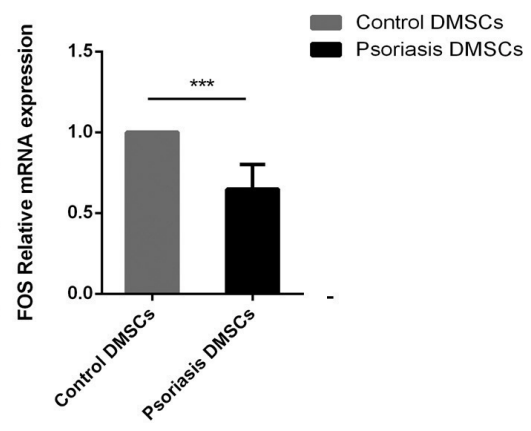

Fig. 3. The proliferation potential of DMSCs. (A, B) The number of normal control DMSCs and psoriatic DMSCs; during long-term culture; on the 3 day. (C, D) JUNB and FOS mRNA expression (psoriasis/control) in the psoriasis and control groups. ns $p>0.05,{ }^{*} p<0.05, * * * p<0.001$.
A

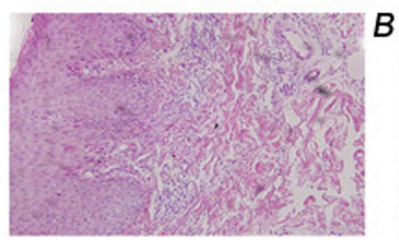

C
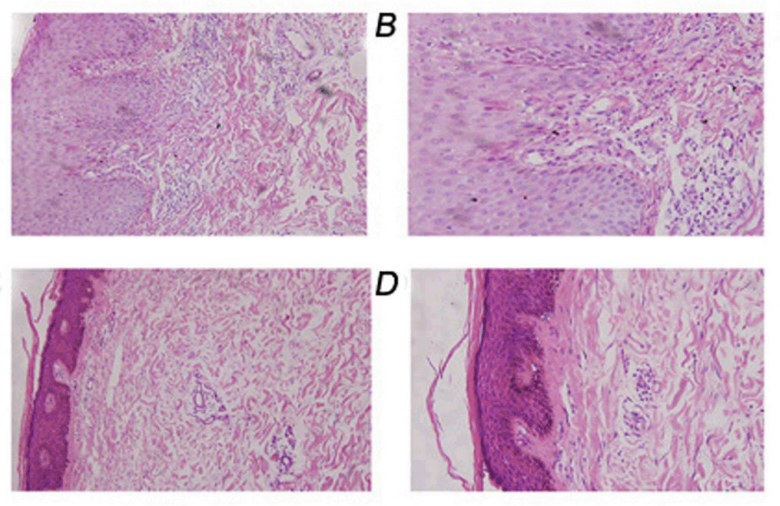

E

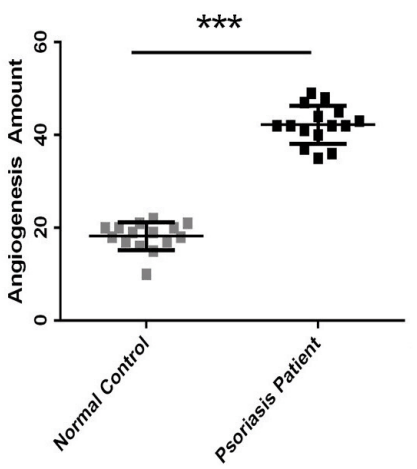

$F$

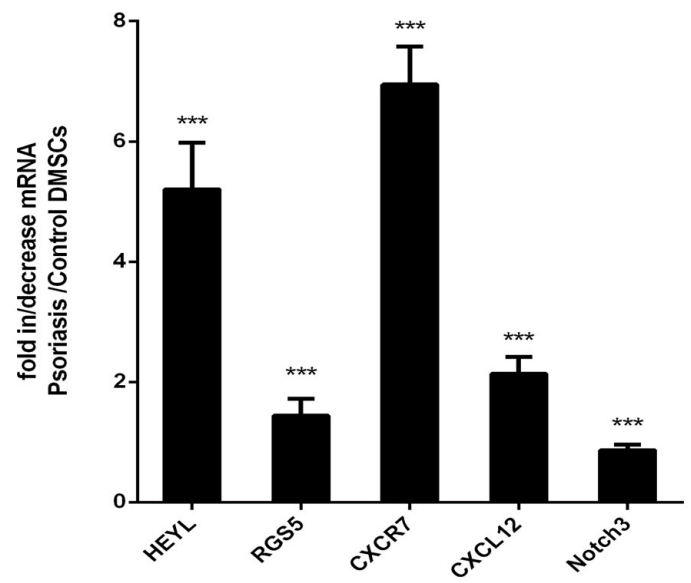

Fig. 4. The number of local blood vessels and the expression of mRNA related to VEC differentiation in the psoriasis and control groups. (A $\sim \mathrm{D})$ Histopathology skin tissue by haematoxylin and eosin (HE) staining as seen under a microscope; $A \& B$ were psoriatic lesions; $C \& D$ were control skin tissue $(A \& C \times 200$ and $B \& D$ $\times 400$, respectively). (E) Blood vessel counts between the psoriasis and control groups. (F) HEYL, CXCR7, CXCL12, RGS5 and Notch3 mRNA relative expression. ${ }^{* * *} \mathrm{p}<0.001$. 


\section{Number of dermal vessels in the two groups}

To investigate the link between glucose metabolism, angiogenesis and VEC differentiation, we examined the blood vessels in psoriatic lesions. After staining, dermal vessels were counted under the microscope. The results showed that the number of dermal vessels in psoriatic lesions and controls were $(42.2 \pm 4.13)$ and (18.2 \pm 3.00$)$ respectively. The number of blood vessels in psoriatic lesions was significantly higher than that in the control group $(\mathrm{p}<0.001)$. The results are shown in Fig. $4 \mathrm{~A} \sim \mathrm{E}$.

\section{Expression of mRNA related to angiogenesis and VEC differentiation}

Our previous research showed that the ability of psoriatic DMSCs to differentiate into VECs in vitro was enhanced compared to normal DMSCs $(17,20)$. To analyse the molecular mechanism of abnormity of local psoriatic blood vessels, the mRNA expression of five mRNAs associated with angiogenesis, VEC differentiation and major factor of signaling pathways was examined with real-time RT-PCR. The analysed mRNAs were CXCR7, CXCL12, RGS5, HEYL, and Notch3. Foure of the five mRNAs were

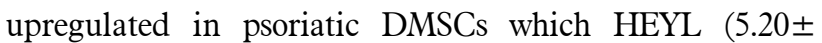
0.78-fold), RGS5 (1.44 \pm 0.28 -fold), CXCR7 (6.95 \pm 0.63 -fold) and CXCL12 (2.13 \pm 0.29 -fold). The mRNA expression of Notch3 was downregulated in psoriatic DMSCs to $(0.86 \pm$ 0.09 -fold) the levels seen in the control. The results are shown in Fig $4 \mathrm{~F}$.

\section{Discussion}

Glucose metabolism is necessary for basic cellular activities and an important metabolic pathway by regulating ATP, nucleotides, and amino acids. It has obvious changes in the development of diseases, and is an important biological indicator (15). Brownstein (21) first suggested that psoriasis may be associated with type 2 diabetes mellitus in 1966 and since then most studies is accumulating suggesting that glucose metabolism in the pathogenesis of psoriatic $(5,22)$. But the results of N. U. Friis were widely conflicting with the studies (16). Therefore, it is necessary to study the metabolic status of DMSCs in patients with psoriasis. We detected the OCR of DMSCs with the Extracellular Flux Analyzer XFe24. The results showed that the OCR of DMSCs from psoriasis patients was significantly higher than control group. Basal respiration, ATP-linked respiration, maximal respiration and reserve capacity were also significantly higher in the psoriatic DMSCs. Choi et al. (23) reported that ablation of Glutl attenuates animal models of psoriasis. HK2 is critically important for aerobic glycolysis (24). We resulted that GLUT1 and HK2 were up-regulated in the psoriatic DMSCs. Upregulation of glucose metabolism is considered to promote hyperproliferation, inflammation and angiogenesis in the pathogenesis of psoriasis. To examine the link between glucose metabolism with DMSC proliferation and local psoriatic blood vessels, we compared the DMSCs of proliferation and angiogenesis derived from psoriatic patient and normal control.

Cell proliferation is an important feature of life and controlled by many factors. FOS are primary oncogenes and subunits of the JUNB (AP-1) transcription factor. FOS combines with JUNB to perform specific cellular functions (25). JUNB participates in multiple physiological processes of cells, including proliferation $(26,27)$. Fan et al. (28) confirmed that knockdown of JUNB significantly inhibited in MM (multiple myeloma) cell proliferation and survival. Martins GA showed that Fos is a component of JUNB, a strong activator of IL-2, which associated with the cell proliferation and survival (29). He et al. (30) suggest that c-fos transcription via the Ras/ ERK1/2 pathway to promote the proliferation of (spermatogonial stem cells) SSC. Glucose is a preferred bioenergetic and synthetic substrate for rapidly proliferating cells, but our results were that the expression of JUNB and FOS was lower in psoriatic DMSCs, corresponding that the cell number on the third day. We preliminarily concluded that FOS and JUNB were involved in the early proliferation regulation of DMSCs in psoriasis.

The typical clinical feature of psoriasis is a squamous erythema or plaque, and vascular hyperplasia is obvious in psoriasis lesions. Vascular abnormalities are affected by many factors, but the exact mechanism remains unclear. Abnormal glucose has been found in many diseases including psoriasis. Our study showed that the number of blood vessels in psoriasis lesions was significantly increased compared to the control group, consistenting with the previous experimental results which psoriatic DMSCs have stronger differentiation function compared to normal DMSCs $(17,31)$. In addition, we studied the mRNA expression levels associated with angiogenesis and differentiation. CXCL12, known as SDF1 (chemokine stromalderived factor-1). The Virgintino et al. (32) supported that in human brain, CXCL12/CXCR7 system appears to be directly involved in microvessel growth, its members being differentially expressed in angiogenically activated microvessels and vascular sprouts. Weng et al. (33) showed that CXCR4/SDF 1 axis was involvement the effects of high glucose on proliferation and function of circulating fibrocytes. RGS5 (regulator of G protein signalling 5) is 
correlated with vascular abnormalities (34). A study confirmed that consistently inhibiting the expression of Notch3, HeyL and Rgs5, affecting the tumor vasculature (35). Notch3 is an important factor in the NOTCH signalling pathway, the NOTCH signalling pathway is an important pathwy related to differentiation, vascular hyperplasia and glucose metabolism (36). HEYL, a primary target genes of Notch, cause congenital heart defects (37). The level of mRNAs showed that CXCL12, CXCR7, HEYL and RGS5 were upregulated in psoriatic DMSCs, in addition to Notch3.

Angiogenic switch has long been considered to be dictated by angiogenic growth factors (eg, vascular endothelial growth factor) and other signals (eg, Notch) alone, but recent findings show that it is also driven by a metabolic switch (38). Vigo et al. (39) pointed out that modifications of MSC energetic metabolism supported a role for metabolic pathways in the therapeutic function of MSC. Zhang Hui, who showed that hPSC (Human Pluripotent Stem Cells) differentiation was accompanied by increased glycolysis and oxidation metabolism levels (40). A number of studies have shown that proliferation, angiogenesis were simultaneously affected by metabolism.

Psoriatic lesions are a complex three-dimensional cell network composed of many cell types. We speculated that abnormal glucose metabolism level of DMSCs affected their own capacity for proliferation, vascular differentiation and the local vascular abnormalities in patients with psoriasis, which resulted in the pathophysiological process of psoriasis. The studies valuable for understanding the pathogenesis of psoriasis.

\section{Acknowledgments}

This work was supported by the National Natural Science Foundation of China (Grant no. 81472888, 81602768, 81803146).

\section{Potential Conflict of Interest}

The authors have no conflicting financial interest.

\section{References}

1. Korman NJ. Management of psoriasis as a systemic disease: what is the evidence? Br J Dermatol 2020;182:840-848

2. Crow JM. Psoriasis uncovered. Nature 2012;492:S50-S51

3. Rapp SR, Feldman SR, Exum ML, Fleischer AB Jr, Reboussin DM. Psoriasis causes as much disability as other major medical diseases. J Am Acad Dermatol 1999;41(3 Pt 1):401-407

4. Ryan C, Kirby B. Psoriasis is a systemic disease with multi- ple cardiovascular and metabolic comorbidities. Dermatol Clin 2015;33:41-55

5. Zhang Z, Zi Z, Lee EE, Zhao J, Contreras DC, South AP, Abel ED, Chong BF, Vandergriff T, Hosler GA, Scherer PE, Mettlen M, Rathmell JC, DeBerardinis RJ, Wang RC. Differential glucose requirement in skin homeostasis and injury identifies a therapeutic target for psoriasis. Nat Med 2018;24:617-627

6. Vieira Paladino F, de Moraes Rodrigues J, da Silva A, Goldberg AC. The immunomodulatory potential of Wharton's jelly mesenchymal stem/stromal cells. Stem Cells Int 2019;2019:3548917

7. Park IS, Chung PS, Ahn JC. Adipose-derived stromal cell cluster with light therapy enhance angiogenesis and skin wound healing in mice. Biochem Biophys Res Commun 2015;462:171-177

8. De Jesus MM, Santiago JS, Trinidad CV, See ME, Semon KR, Fernandez MO Jr, Chung FS. Autologous adipose-derived mesenchymal stromal cells for the treatment of psoriasis vulgaris and psoriatic arthritis: a case report. Cell Transplant 2016;25:2063-2069

9. Chen H, Niu JW, Ning HM, Pan X, Li XB, Li Y, Wang $\mathrm{DH}$, Hu LD, Sheng HX, Xu M, Zhang L, Zhang B. Treatment of psoriasis with mesenchymal stem cells. Am J Med 2016;129:e13-e14

10. Liu R, Yang Y, Yan X, Zhang K. Abnormalities in cytokine secretion from mesenchymal stem cells in psoriatic skin lesions. Eur J Dermatol 2013;23:600-607

11. Hou R, Yin G, An P, Wang C, Liu R, Yang Y, Yan X, Li J, Li X, Zhang K. DNA methylation of dermal MSCs in psoriasis: identification of epigenetically dysregulated genes. J Dermatol Sci 2013;72:103-109

12. Li J, Xing J, Lu F, Chang W, Liang N, Li J, Wang Y, Li $\mathrm{X}$, Zhao X, Hou R, Man M, Yin G, Li X, Zhang $\mathrm{K}$. Psoriatic dermal-derived mesenchymal stem cells reduce keratinocyte junctions, and increase glycolysis. Acta Derm Venereol 2020;100:adv00122

13. Cheng H, Qiu L, Zhang H, Cheng M, Li W, Zhao X, Liu K, Lei L, Ma J. Arsenic trioxide promotes senescence and regulates the balance of adipogenic and osteogenic differentiation in human mesenchymal stem cells. Acta Biochim Biophys Sin (Shanghai) 2011;43:204-209

14. Zhou L, Niu X, Liang J, Li J, Li J, Cheng Y, Meng Y, Wang Q, Yang X, Wang G, Shi Y, Dang E, Zhang K. Efficient differentiation of vascular endothelial cells from dermal-derived mesenchymal stem cells induced by endothelial cell lines conditioned medium. Acta Histochem 2018;120:734-740

15. Mulukutla BC, Yongky A, Le T, Mashek DG, Hu WS. Regulation of glucose metabolism - a perspective from cell bioprocessing. Trends Biotechnol 2016;34:638-651

16. Friis NU, Hoffmann N, Gyldenlove M, Skov L, Vilsboll T, Knop FK, Storgaard H. Glucose metabolism in patients with psoriasis. Br J Dermatol 2019;180:264-271

17. Li J, Zhou L, Liang J, Liu Y, Li J, Hou H, Hou R, Niu X, Li J, Liu R, Zhao X, Meng Y, Yang X, Wang G, Shi 
Y, Dang E, Zhang K. Psoriatic mesenchymal stem cells demonstrate an enhanced ability to differentiate into vascular endothelial cells. Eur J Dermatol 2018;28:688-690

18. Hodeib AA, Neinaa YME, Zakaria SS, Alshenawy HA. Glucose transporter-1 (GLUT-1) expression in psoriasis: correlation with disease severity. Int J Dermatol 2018;57: 943-951

19. Roberts DJ, Miyamoto S. Hexokinase II integrates energy metabolism and cellular protection: akting on mitochondria and TORCing to autophagy. Cell Death Differ 2015;22:248257

20. Hou R, Yan H, Niu X, Chang W, An P, Wang C, Yang Y, Yan X, Li J, Liu R, Li X, Zhang K. Gene expression profile of dermal mesenchymal stem cells from patients with psoriasis. J Eur Acad Dermatol Venereol 2014;28:17821791

21. Brownstein MH. Psoriasis and diabetes mellitus. Arch Dermatol 1966;93:654-655

22. Makuch S, Woźniak M, Krawczyk M, Pastuch-Gawołek G, Szeja W, Agrawal S. Glycoconjugation as a promising treatment strategy for psoriasis. J Pharmacol Exp Ther 2020; 373:204-212

23. Choi SY, Heo MJ, Lee C, Choi YM, An IS, Bae S, An S, Jung JH. 2-deoxy-d-glucose Ameliorates animal models of dermatitis. Biomedicines 2020;8:20

24. Gill KS, Fernandes P, O'Donovan TR, McKenna SL, Doddakula KK, Power DG, Soden DM, Forde PF. Glycolysis inhibition as a cancer treatment and its role in an anti-tumour immune response. Biochim Biophys Acta 2016;1866:87-105

25. Alfonso-Gonzalez C, Riesgo-Escovar JR. Fos metamorphoses: lessons from mutants in model organisms. Mech Dev 2018;154:73-81

26. Zhao L, Huang J, Guo R, Wang Y, Chen D, Xing L. Smurfl inhibits mesenchymal stem cell proliferation and differentiation into osteoblasts through JunB degradation. J Bone Miner Res 2010;25:1246-1256

27. Chiu R, Boyle WJ, Meek J, Smeal T, Hunter T, Karin M. The c-Fos protein interacts with c-Jun/AP-1 to stimulate transcription of AP-1 responsive genes. Cell 1988;54:541552

28. Fan F, Bashari MH, Morelli E, Tonon G, Malvestiti S, Vallet S, Jarahian M, Seckinger A, Hose D, Bakiri L, Sun C, Hu Y, Ball CR, Glimm H, Sattler M, Goldschmidt H, Wagner EF, Tassone P, Jaeger D, Podar K. The AP-1 transcription factor JunB is essential for multiple myeloma cell proliferation and drug resistance in the bone marrow microenvironment. Leukemia 2017;31:1570-1581

29. Martins GA, Cimmino L, Liao J, Magnusdottir E, Calame K. Blimp-1 directly represses Il2 and the Il2 activator Fos, attenuating $\mathrm{T}$ cell proliferation and survival. J Exp Med
2008;205:1959-1965

30. He Z, Jiang J, Kokkinaki M, Golestaneh N, Hofmann MC, Dym M. Gdnf upregulates c-Fos transcription via the Ras/Erk1/2 pathway to promote mouse spermatogonial stem cell proliferation. Stem Cells 2008;26:266-278

31. Salem HK, Thiemermann C. Mesenchymal stromal cells: current understanding and clinical status. Stem Cells 2010;28:585-596

32. Virgintino D, Errede M, Rizzi M, Girolamo F, Strippoli M, Wälchli T, Robertson D, Frei K, Roncali L. The CXCL12/CXCR4/CXCR7 ligand-receptor system regulates neuro-glio-vascular interactions and vessel growth during human brain development. J Inherit Metab Dis 2013;36: 455-466

33. Weng Y, Lou J, Liu X, Lin S, Xu C, Du C, Tang L. Effects of high glucose on proliferation and function of circulating fibrocytes: involvement of CXCR4/SDF-1 axis. Int J Mol Med 2019;44:927-938

34. Hurst JH, Hooks SB. Regulator of G-protein signaling (RGS) proteins in cancer biology. Biochem Pharmacol 2009;78:1289-1297

35. Yen WC, Fischer MM, Axelrod F, Bond C, Cain J, Cancilla B, Henner WR, Meisner R, Sato A, Shah J, Tang T, Wallace B, Wang M, Zhang C, Kapoun AM, Lewicki J, Gurney A, Hoey T. Targeting Notch signaling with a Notch2/Notch3 antagonist (tarextumab) inhibits tumor growth and decreases tumor-initiating cell frequency. Clin Cancer Res 2015;21:2084-2095

36. Lee SY, Long F. Notch signaling suppresses glucose metabolism in mesenchymal progenitors to restrict osteoblast differentiation. J Clin Invest 2018;128:5573-5586

37. Fischer A, Steidl C, Wagner TU, Lang E, Jakob PM, Friedl P, Knobeloch KP, Gessler M. Combined loss of Heyl and HeyL causes congenital heart defects because of impaired epithelial to mesenchymal transition. Circ Res 2007;100: 856-863

38. Eelen G, de Zeeuw P, Simons M, Carmeliet P. Endothelial cell metabolism in normal and diseased vasculature. Circ Res 2015;116:1231-1244

39. Vigo T, La Rocca C, Faicchia D, Procaccini C, Ruggieri $M$, Salvetti M, Centonze D, Matarese G, Uccelli A. IFN $\beta$ enhances mesenchymal stromal (Stem) cells immunomodulatory function through STAT1-3 activation and mTOR-associated promotion of glucose metabolism. Cell Death Dis 2019;10:85

40. Zhang H, Badur MG, Divakaruni AS, Parker SJ, Jäger C, Hiller K, Murphy AN, Metallo CM. Distinct metabolic states can support self-renewal and lipogenesis in human pluripotent stem cells under different culture conditions. Cell Rep 2016;16:1536-1547 